\title{
Uncertainty-based Multi-objective Modeling for Short- term Demand Response Program Scheduling in the Presence of Retail Electricity Providers
}

\author{
Faramarz Separi $^{1} \quad$ Abdolreza Sheikholeslami $^{2} \quad$ Taghi Barforoshi $^{3}$ \\ ${ }^{1}$ Ph.D. Student, Department of Electrical Engineering, Faculty of Electrical and Computer Engineering, \\ Babol Nooshirvani University of Technology, Babol, Iran \\ Fa_separi@yahoo.com \\ ${ }^{2}$ Associate Professor, Department of Electrical Engineering, Faculty of Electrical and Computer Engineering, \\ Babol Nooshirvani University of Technology, Babol, Iran \\ asheikh@nit.ac.ir \\ ${ }^{3}$ Assistant Professor, Department of Electrical Engineering, Faculty of Electrical and Computer Engineering, \\ Babol Nooshirvani University of Technology, Babol, Iran \\ barforoshi@nit.ac.ir
}

\begin{abstract}
:
In this paper, the short-term scheduling for demand response program (DRP) with retail electricity providers (REPs) with light physical assets is proposed. The main contribution is to determine an optimal multi-objective model for these REPs to integrate them into design-model of the incentive-based DRP for retail markets, considering load uncertainties on the locational marginal prices (LMP). Fuzzy logic modeling is used for simulating load uncertainty. Non-dominated sorting genetic algorithm (NSGA-II) is used, due to non-linearity and thus the complexity of the proposed model. A non-linear sorting system based on fuzzy logic is also utilized to find the best compromise among the set of solutions generated by the Pareto-front space. IEEE 24 bus reliability test system is utilized to explain the optimal performance of the proposed approach.
\end{abstract}

Keywords: Demand Response Program, Retail Electricity Providers, Locational Marginal Prices, Uncertainty, NSGA-II.

Article Type: Research paper

Submission date: 05, May. 2019

Conditional Acceptance date: 21, Aug. 2019

Acceptance date : 15, Jan. 2020

Corresponding author : Abdolreza Sheikholeslami

Corresponding author's address: Shariati Ave. Power.Elec. Dep., Babol Nooshirvani Uni. Of Tech. Babol , Iran.,

Post Code: 47148-71167. 


\section{Introduction}

The gap between wholesale electricity markets and endusers can be bridged by retail electricity providers (REP's) in market discussions. In addition to the forward contracts, the REP's as a mediator role in electricity markets purchase part of the consuming demand through the pool market [1]. Different factors such as price variations, volatile loads and the potential for market power exertion by generation companies may bring financial risks to retail electricity providers.

A retail electricity provider can manage the market risks by employing the demand response programs. The REP's can propose the selling price based on fixed tariffs, time-of-use price or real-time price during the contract period. Moreover, due to the risk in the market price, the electricity consumers can retain themselves through long-term contracts which are held with REP's. In these circumstances; the REP's can implement a combination of approaches to manage the financial risks to be protected from the wholesale markets' risks [2]. One way to reduce the risk is well-designed demand response program (DRP). The U.S. DRP is defined as the ability of residential, commercial and industrial to modify the electrical energy-consumption patterns as a response to changes in electricity prices over the time or to incentive payments to find rational prices and reliability of the network. The DRP can be categorized into two groups based on this definition [3]: time-based rates and incentive-based programs. For example, a combination of time incentive based demand response program, and real time pricing was proposed in [4] to reduce the peak load through energy management at the customers' side.

To implement the DRP, it is necessary that consumers are equipped with smart meters. Finally, DRP can be exploited by the REP's as an option enabled through smart technology to enhance the anticipated benefit. Moreover, with the modern smart technologies in grids and home energy management systems, the DRPs could be effectively used by electricity consumers to moderate some financial risks [5].

Another way to overcome risk is making use of distributed generation (DG) and energy storage systems (ESSs) owned by REP's, during price spikes. The REP's with light physical assets, such as DG and ESS, serve electricity end-users in the distribution level [6]. The effect of energy storage systems have been studied by many researchers [7, 8]. Reference [7] investigates the participation of energy storage systems in the demand response program by proposing two scheduling algorithms.

There are various papers focusing on REP's for specification of selling at three time periods containing short-term, medium-term and long-term scheduling. In long-term scheduling, references [9, 10] minimize total cost without pricing, DRP, smart meter technology and maximizing the anticipated benefit considering uncertainty modeling is proposed. Therewith, the review of studies related to medium-term scheduling shows that the objective function is minimizing cost [11, 12], maximizing benefit [13-15]. Furthermore, the solution technique is based on hybrid heuristic algorithm or GAMS optimization package. Finally, the researches related to short-term scheduling show that the objective function is maximizing benefit [17-20] [21] and minimizing cost [22-24]. Unlike the two time periods above, real-time pricing as well as fixed pricing and timeof-use pricing are exploited as types of selling price in short-term scheduling. Reference [25] used real-time pricing in the retail price determination problem in the smart grid to increase retailer' profit. The load uncertainty modeling is not considered for locational marginal price (LMP) in the presented papers. Also, few studies in the literature attempt to take into account the DRP in the energy supply procurement problem of the REP's based on a multi-objective optimization model. Only, Ref. [26] proposes a multi-objective optimization for planning direct load control for a group of customers from the viewpoint of retailers.

In this paper, the short-term scheduling for DRP with asset-light retailers is proposed. The main idea is to determine an optimal chassis for these retail electricity providers to cooperate them in designing the optimal incentive-based DRP in retail markets, considering the short-term advantages and load uncertainties on locational marginal prices (LMP). It is assumed that the DISTCO's do not participate in the suggested DRP and the only REP's and consumers are involved in the suggested DRP. Short-term DRP scheduling of the lightasset retailers who provide the electricity consumers is formulated through a multi-objective optimization model with practical operational limitations. This type of scheduling supports the REP's to decrease the peak periods at the nodes that they provide to the customers. In this paper, the non-dominated sorting genetic algorithm (NSGA-II) [27] is used to solve the multi-objective optimization which maintains the diversity of the solutions by providing a crowding distance sorting approach. The innovation of this work is organized around three important matters:

- Formulate the short-term scheduling for DRP as a multi-objective optimization model.

- The load uncertainty on the LMPs is characterized.

- Solving multi-objective optimization by NSGA-II as a robust GA-based algorithm to choose the best compromise solution from a set of Pareto solutions.

In addition, the main contributions are illustrated as follows:

- Provide an optimal incentive-based demand response program to electricity retailers to reduce the financial losses in the market.

- Only the retailers and the customers are involved in the proposed demand response program.

- Consideration of energy generation and storage units effect in the demand response program to manage the market price by the electricity retailer.

- Investigation of the demand-side reserve role in the energy market. 
The structure of the paper is targeted as follows. The multi-objective model for optimal short-term DRP scheduling with REP's under different problem constraints is presented in section 2. In Section 3, the load uncertainties on the locational marginal prices are modeled. The multi-objective optimization algorithm is presented in Section 4. A test system is simulated and analyzed in Section 5. Finally, the relevant conclusions are introduced in Section 6.

\section{Proposed Framework}

The REP's can employ new instruments and approaches or make use of different strategies to reduce risks linked to the severe market price variations. In this regard, this paper targets to present how a REP's with few generation units as well as storages employs the DRPs to manage the varieties of the power energy market. Ref [6] was introduced the REP's with light physical assets as assetlight retailer. If strategies applied by REP to avoid shortterm financial or economical losses are wellpremeditated, they can obtain additional profits for the REP's. In the smart grids, the DRPs can be exploited for flexible load management to reduce peak load and the purchased energy cost [28]. The fundamental goal of this study is to formulate a model to determine the hourly financial incentives suggested to the consumers for shortterm horizon. The short-term DRP scheduling of the asset-light retailers who provide the electricity consumers is analyzed in this paper as a multi-objective optimization problem with practical operational limitations. In this proposed model, to avoid the high network costs in the long-term, the REP's have several options to moderate their daily profit. The asset-light REP's contain a few light physical assets, such as DG units and ESSs in the distribution network. Considering that every battery technology has its own economic and technical properties, it is necessary to decide which battery technology is the most suitable choice in distribution networks. In this paper, the characteristics of Sodiumsulfur battery $(\mathrm{Na}-\mathrm{S})$ and Zinc-bromine battery $(\mathrm{Zn}-\mathrm{Br})$ are investigated [29]. The retailer determine the optimal demand bids, based on the dispatching decisions of its' DG units and/or different types of ESSs for the day ahead. These intentions can affect the optimal financial incentives offered to customers to persuade them to adapt their consumption profile. In order to clarity and simplicity the assumptions are given below:

- The model assumes that the REP's are price-taker in the wholesale electricity market. The considered REP's are price-taker, which means that it has no ability to change the electricity prices in the market. Prices in the market are behaved as an exogenous parameter.

- DGs and ESSs in this model that belong to retailer, just submit power demand bids and do not offer their generation and storage capacity to sell energy in the wholesale market.

- The different types of battery technology are considered.
- The uncertainty of the battery technological behavior for optimal battery planning is taken into account. This important issue is addressed using the fuzzy models and operators.

- The load is considered as uncertainly data.

\subsection{Fuzzy Logic Based Uncertainty Modeling}

Different battery technologies show different behavior based due to their different characteristics, however the technical and economical behavior is not deterministic. The uncertainty of the behavior has to be taken into account in a comparative study. For example, the uncertainty of the cost of capacity in Figure 1 is shown using box plots. In each box segment, the data is given for example, the data as example average (median), the interquartile range (middle fifty) and range (excluding outliers) is presented [30].

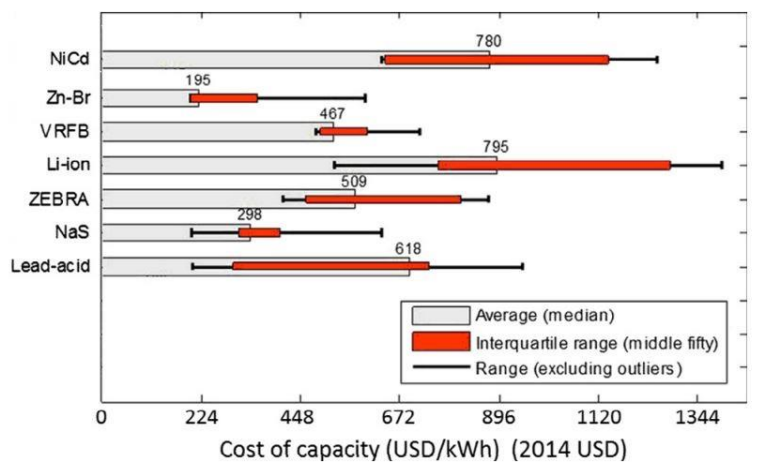

Fig. 1. Variations of capacity cost as well as the average

For probabilistic studies the middle fifty or the range (excluding outliers) are used for modeling uncertainty, while the average data is taken into use in deterministic studies. We have defined two fuzzy values for each parameter accordingly. The triangular fuzzy values assigned to middle fifty and the range (excluding outliers) are shown in figure 2. Both models dedicate the maximum membership function to the average cost [31].

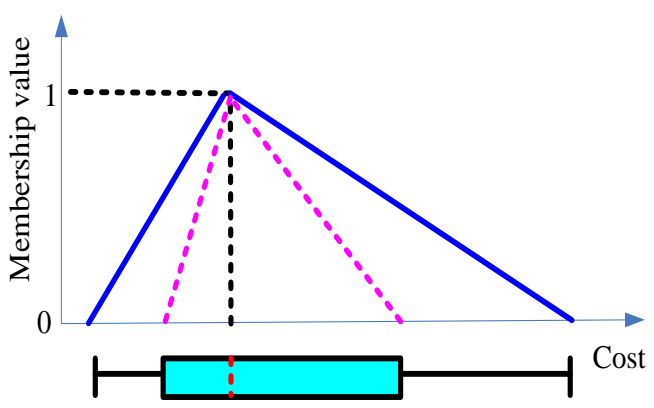

Fig. 2. Dedication of triangular fuzzy values to a box plot

The middle fifty models contain the most possible situations .When using the model of range (excluding outliers) the uncertainty intensifies $[32,33]$. 


\subsection{Battery Technologies}

Rechargeable batteries are categorized into several types based on their structures, used materials, and the mechanism of storage. Any battery type has its own planning criteria. Capacity cost in $\$ / \mathrm{kWh}$, power rating investment cost in $\$ / \mathrm{kW}$, costs of battery replacement in $\$ / \mathrm{kWh}$, yearly O\&M costs in $\$ / \mathrm{kW}$, total efficiency, maximum depth of charge limit, and the total length of life, indicated in number of charge/discharge cycles, are the key considerations for optimal battery sizing. We have concentrated on Sodium-sulfur batteries' (Na-S) and Zinc-bromine batteries' ( $\mathrm{Zn}-\mathrm{Br})$ characteristics in this research. Reference [34] gives a comprehensive review on these technologies with detailed technical and economic considerations. Table 1 compares the two technologies, where the presented values are the mean values given by a distribution range.

Table. 1. The mean value of parameters of the battery technologies [34]

\begin{tabular}{|l|l|l|l|l|l|}
\hline $\begin{array}{l}\text { Type } \\
\text { of } \\
\text { battery }\end{array}$ & $\begin{array}{l}\text { Capacity } \\
\text { cost } \\
(\$ / \mathrm{kWh})\end{array}$ & $\begin{array}{l}\text { Power } \\
\text { rating } \\
\operatorname{cost}(\$ / \mathrm{kW})\end{array}$ & $\begin{array}{l}\text { Replacement } \\
\operatorname{cost}(\$ / \mathrm{kWh})\end{array}$ & $\begin{array}{l}\text { O\&M } \\
\text { cost } \\
(\$ / \mathrm{kW}- \\
\text { year })\end{array}$ & $\begin{array}{l}\text { Efficiency } \\
(\%)\end{array}$ \\
\hline $\mathrm{Na}-\mathrm{S}$ & 363 & 446 & 219 & 4.4 & 83 \\
\hline $\mathrm{Zn}-\mathrm{Br}$ & 238 & 541 & 238 & 5.2 & 65 \\
\hline
\end{tabular}

\subsection{Objective Functions}

The objective functions of this paper are considered as REP's payoff and total peak demand as follows.

\subsubsection{REP's Payoff Based Objective Function}

The retail electricity providers can increase the shortterm payoff by using their generation/ storage facilities in the distribution network and the DRPs. Employing this model, the REP's will tend to use their own resources during periods with high market price. In Eq. (1), the ESSs' charging energy is purchased from the market, and the related cost of charging is calculated based on the uncertainty of LMPs. The cost of DG units consists of the startup cost and the quadratic cost function [35]. The first objective function that will be maximized is as follows:

Payoff $_{x}=\sum_{b \in \Omega_{x}} \sum_{t=1}^{T}\left[\sum_{c \in \Omega_{x}^{b-c}}\left(R_{c}^{t} \cdot\left(I_{c}^{t}-\Delta I_{c}^{t}\right)\right)-L M P_{b}^{t} \cdot w_{d}^{t}-C G(t)-C D G(t)-C E S S(t)-F I(t)\right]$

Where,

$$
C G(t)=\sum_{g \in \Omega_{x}^{b-G}}\left(\alpha_{g} \cdot u_{g}^{t}+\beta_{g} \cdot P_{g}^{t}+\gamma_{g} \cdot\left(P_{g}^{t}\right)^{2}+c_{g}^{\text {start }} \cdot v_{g}^{t}\right)
$$

$$
C D G(t)=\sum_{i \in \Omega_{x}^{b-D G}} c_{g}^{p} \cdot P_{g}^{t}
$$

$$
\operatorname{CESS}(t)=\sum_{s \in \Omega_{x}^{b-E S S}} c_{s}^{\mathrm{deg}} \cdot P_{s}^{\text {out } t \text { t }}
$$

$$
F I(t)=\sum_{c \in \Omega_{x}^{b}}\left(F i_{b}^{t} \cdot \Delta I_{c}^{b} \cdot m_{c}^{t}\right)
$$

Where $\mathrm{t}$ is time periods (h), b is buses, $\mathrm{c}$ is the end use electricity customers, $\mathrm{g}$ is number of DGs, $\mathrm{s}$ is number of
ESSs, $P_{g}$ is real power output of the $\mathrm{g}^{\text {th }} \mathrm{DG}(\mathrm{kW}), u_{g}$ is a binary variable which shows the commitment status of the $\mathrm{g}^{\text {th }}$ DG unit (1 means the unit is on), $v_{g}$ is binary variable indicating start-up status of the $g^{\text {th }}$ DG ( 1 means the unit starts up at the beginning of $\mathrm{t}^{\text {th }}$ period), $P_{s}^{\text {in/out }}$ is the charging/discharging power of ESS $s$ during each time period $(\mathrm{kWh}), m_{c}$ is a binary variable indicating the time periods at which the retailer should send incentives to the customers ( 1 means that incentives should be sent to the $\mathrm{c}^{\text {th }}$ customer by the retailer), FI is financial incentive for DR in DAM $(\$ / \mathrm{kW} \mathrm{h}), \Delta I$ is the expected demand reduction by the $c^{\text {th }}$ customer $(\mathrm{kW}), \mathrm{T}$ is the time horizon for scheduling (in number of time periods), $(\alpha, \beta, \delta)_{g}$ are quadratic cost coefficients of the $\mathrm{g}^{\mathrm{tj}}$ controllable DG unit $(\$ / \mathrm{h}, \$ / \mathrm{kW} \mathrm{h}, \$ /(\mathrm{kW} \mathrm{h}) 2), C_{g}^{\text {start }}$ is start-up cost of the $\mathrm{g}^{\text {th }}$ controllable DG unit $(\$), C_{g}^{p}$ is production cost of the $\mathrm{g}^{\text {th }}$ uncontrollable DG unit $(\$ / \mathrm{kWh})$ and $R_{c}$ is the electricity price offer by retailers.

\subsubsection{Peak Demand Based Objective Function}

The second objective function to minimize is the total peak demand at all buses served by REPs according to Eq. (6).

$$
\sum_{b \in \Omega_{j}} M_{b}
$$

Where $M_{b}$ is the peak demand at bus b.

\subsection{Constraints}

The constraints of the proposed objective functions are explained as follow:

\subsubsection{Purchase Limit}

Eq. (8) is applied to the objective function (6) to minimize the maximum demand at each bus.

$$
w_{b}^{t}=\sum_{c \in \Omega_{x}^{b^{b}}}\left(I_{c}^{t}-\Delta I_{c}^{t}\right)+\sum_{s \in \Omega_{x}^{b-E S S}} p_{s}^{i n, t}-\sum_{s \in \Omega_{x}^{b-E S S s}} p_{s}^{o u t, t}-\sum_{g \in \Omega_{x}^{b-G}} p_{g}^{t}-\sum_{g \in \Omega_{x}^{b-D G}} p_{g}^{t} \quad \forall t, \forall b
$$

Where $w_{b}$ is the electrical energy which is purchased from the wholesale market by retailer at bus $\mathrm{b}(\mathrm{kW})$.

\subsubsection{Real Power Generation Limit}

The proposed model assumes that the generated electricity of DG units is as high as their maximum installed capacity. The lower and upper bounds of any DG unit limit the active power output as follows:

Where $P_{g}^{\text {MinlMax }}$ is minimum/maximum power generation of the $\mathrm{g}^{\text {th }} \mathrm{DG}$ unit $(\mathrm{kW})$.

Constraint (11) demonstrates the relation between the unit commitment and binary decision variables of startup, shut down. 


\subsubsection{Battery Limit}

The charging/discharging power of a battery is surrounded by the capacity and the rated power of ESS [36].

$$
\begin{aligned}
& p_{s}^{\text {out }, t} \leq R_{s}^{\text {out,max }} \cdot k_{s}^{t} \\
& p_{s}^{\text {in,t }} \leq R_{s}^{\text {in,max }} \cdot h_{s}^{t} \\
& E_{s}^{\min } \leq E_{s}^{\text {stored }, t} \leq E_{s}^{\max } \\
& E_{s}^{\text {stored,t }}=\eta_{s}^{\text {in. }} \cdot p_{s}^{\text {in,t }}-\frac{1}{\eta_{s}^{\text {out }}} \cdot p_{s}^{\text {out,t }}+\lambda \cdot E_{s}^{\text {stored, } t-1}+(1-\lambda) \cdot E_{s}^{\text {initial }} \\
& \lambda= \begin{cases}\lambda=0 & t=1 \\
\lambda=1 & \text { other }\end{cases} \\
& k_{s}^{t}+h_{s}^{t} \leq 1
\end{aligned}
$$

Where $E_{s}^{\text {MinlMax }}$ is the minimum or maximum storage level of the $\mathrm{s}^{\text {th }} \mathrm{ESS}(\mathrm{kWh}), R_{s}^{\text {in,MinlMax }}$ minimum or maximum charging rate of the $\mathrm{s}^{\text {th }}$ ESS $(\mathrm{kW} / \mathrm{h})$, $R_{s}^{\text {out,MinlMax }}$ is minimum or maximum discharge rate of the $\mathrm{s}^{\text {th }}$ ESS $\mathrm{s}(\mathrm{kW} / \mathrm{h}), k_{s}$ is binary variable which indicates discharging status of the $s^{\text {th }}$ ESS (1 means it is being discharged), $h_{s}$ is a binary variable which indicates charging status of the $s^{\text {th }}$ ESS (1 means it is being charged) and $E_{s}^{\text {stored }}$ is the storage level of the $\mathrm{s}^{\text {th }}$ ESS at the end of each time period (kWh).

Eq. (13) indicates the charging and discharging power at each time period of the scheduling horizon. Imposed constraint of Eq. (14) excludes the simultaneous charge/discharge activities in any time period.

\subsubsection{Financial Incentives Limitation}

The incentives of the DRP are suggested only for hours that the customer is expected to consume more than the nominal load profile. A stream of revenue could be reached by the customer within this step. Each kWh less than the forecasted load is rewarded by the REPS for the hours that the retail electricity providers offer financial incentives. Limitation is expressed as the below:

$$
\begin{aligned}
& w_{b}^{t}-M_{b} \leq 0 \quad \forall t, \forall b \\
& \Delta I_{c}^{t}=m_{c}^{t} \cdot f_{c}\left(F i_{c}^{t}\right) \\
& m_{c}^{t} \cdot F i_{c}^{\min } \leq F i_{c}^{t} \leq m_{c}^{t} \cdot F i_{c}^{\max }
\end{aligned}
$$

\section{Impact of Load on LMPs}

$$
P_{g}^{\min } \cdot u_{g}^{t} \leq P_{g}^{t} \leq P_{g}^{\max } \cdot u_{g}^{t}
$$

Locational marginal price is defined as the marginal cost of supplying the next increment of electric energy at a specific bus while considering the generation marginal cost and the physical aspects of the transmission system. Social welfare is the difference between the costs of the generated $c(p)$ energy and the consumers' benefits $B(p)$ :

Social Welfare: $\sum B(p)-c(p)$

The clearing price is determined by optimizing this function with the Independent System Operator (ISO) considering the constraints of the system. In most cases, there is either no specific formula for $B(p)$ or it is very complex. As a consequence, $B(p)$ is neglected and the following function is minimized (according to the negative sign) [37]:

$\min \left(\sum_{i=1}^{n} C_{i}(p)\right)$

Where, $c_{i}(p)$ is the cost function of every generator and is usually explained with $C_{i}=a p^{2}+b p+c_{0}$ in which $\mathrm{n}$ is the number of generators and $\mathrm{P}$ is the generated power. Equation (17) can be solved based on DCOPF [38]. In this situation, the Lagrange function of optimization problem is derived as follows:

$$
l=\sum_{i=1}^{n} C\left(I_{i}\right)+\sum_{i=1}^{n} \pi_{i}\left[I_{i}-\sum_{j=1}^{n} Y_{i j}\left(\theta_{i}-\theta_{j}\right)\right]+\sum_{i=1}^{n} \sum_{j=1}^{n} \mu_{i j}\left[P_{i j}^{\max }-Y_{i j}\left(\theta_{i}-\theta_{j}\right)\right]
$$

In (18), $\pi_{i}$ is the LMP for the bus $i, \theta_{i}$ is the angle of bus i, $Y_{i j}$ is the ith row and jth column of the admittance matrix, $\mu$ is the coefficient related to spot price and $I_{i}$ is the injected power.

It should be noted that according to DC load flow, cost of power loss has been neglected $[37,38]$.

\section{Multi-objective Solution Strategy}

Non-dominated sorting based approach is accommodated combining with the genetic algorithm to optimize the multiple objective problems. The multi-objective solution strategy is calibrated with regards to the limitation of the Pareto solutions. In this paper, the NSGA-II is programmed to analyze the multi-objective problem because it has been proved to be one of the most efficient algorithms subject to definite constraints. The multicriteria problem including $\mathrm{m}$ objectives, which generally otherness with each other, could be calculated as:

Optimize $\left[F_{1}(x, u), F_{2}(x, u), \ldots, F_{N P}(x, u)\right] \quad N P=1,2, \ldots, m$

To perform of this strategy, the control variables are randomly generated as initial population. After evaluating the objective functions, a non-dominated 
sorting strategy is exploited on the calculated solutions to find a Pareto set. The most effective Pareto set is achieved by comparison procedure. Sorting process is exploited to classify the greatest solutions in the optimal Pareto set. Fuzzy based decision mechanism is employed to select the greatest compromised solutions depending on the issue requirements.

\subsection{Non-Dominated Sorting}

A non-dominated sorting methodology is placed on the multi-objective optimization to get the optimal Pareto set. Let us suppose two solutions F1 and F2, in a single optimal Pareto set. They are investigated for the next possibilities: one overcomes another or not one of them dominates each other. A design vector u1 overcomes $\mathrm{u} 2$, when the next conditions are satisfied:

$$
\begin{array}{ll}
\forall i=1,2, \ldots, m & F_{i}\left(u_{1}\right) \leq F_{i}\left(u_{2}\right) \\
\exists \quad j=1,2, \ldots, m & F_{j}\left(u_{1}\right) \leq F_{j}\left(u_{2}\right)
\end{array}
$$

The sorting procedure is exploited to acquire the most effective Pareto set solutions. Solutions which can be non-dominated over the entire search space are called optimal Pareto set front and build the Pareto front set.

\subsection{Fuzzy Decision Making}

Since acquiring the greatest Pareto set solutions, the most effective compromised solution predicted on a choice prepared is extracted by the designer. The fuzzy based decision mechanism is exploited to acquire the optimal Pareto set solution. Membership value is funded for the ith objective using Eq. (21) [36, 39] in the jth Pareto optimal solution.

$$
\mu_{i}^{j}=\left\{\begin{array}{lc}
1 & F_{i}^{j}<\min \left(F_{i}\right) \\
\frac{\max \left(F_{i}\right)-F_{i}^{j}}{\max \left(F_{i}\right)-\min \left(F_{i}\right)} & \min \left(F_{i}\right) \leq F_{i}^{j}<\max \left(F_{i}\right) \\
0 & F_{i}^{j}>\max \left(F_{i}\right)
\end{array}\right.
$$

This value for qth Pareto front solution can be performed by using of Eq. (22).

$$
\mu_{\text {opt }}=\sup \left\{\frac{\sum_{p=1}^{m} W_{p} \mu_{p}^{q}}{\sum_{q=1}^{N_{\text {PFS }}} \sum_{p=1}^{m} W_{p} \mu_{p}^{q}}\right\}
$$

Where, $W_{p}$ is the weight ratio of the pth fitness function and NPFS is the total amount of solutions in the most effective Pareto set. Preferred level of the Pareto set solutions can be recognized across normalized values.

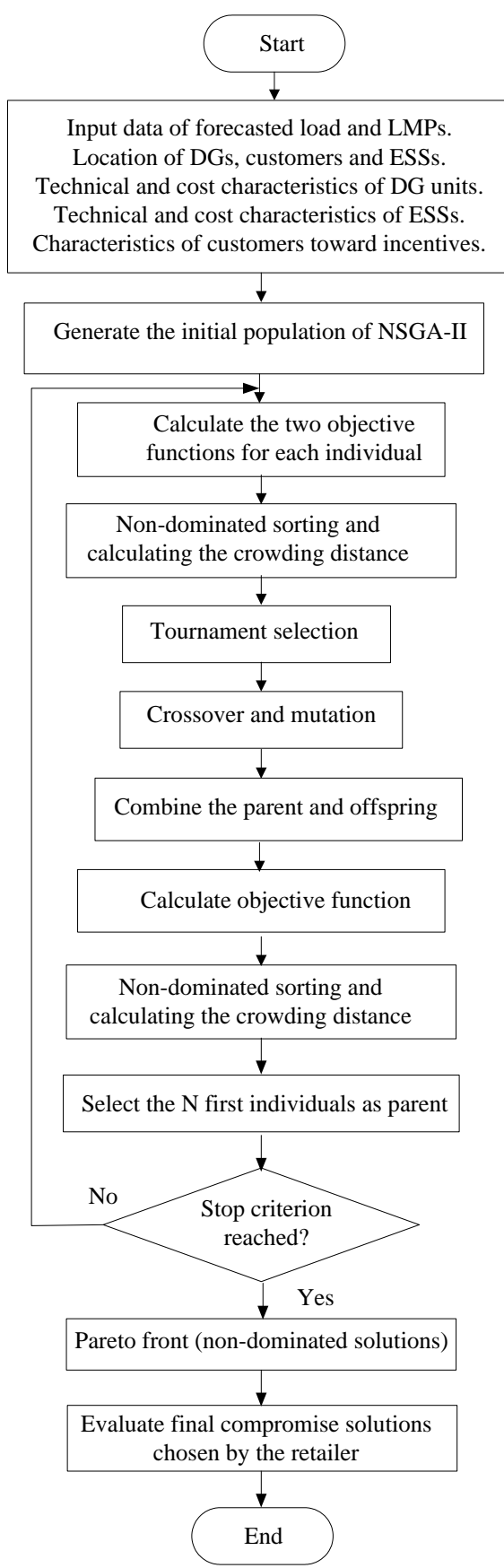

Fig. 3. Flowchart for multi-objective optimization problem of retailers based on NSGA-II.

\subsection{Optimization Procedure}

The proposed multi-objective model for REPs involves control variables. The initialization process is designed so that the algorithm starts with a feasible population for energy storage value of ESSs, generation level of DG units, financial incentives and always makes feasible candidates during the crossover and mutation operators [40]. The $\mathrm{Mb}$ is another control variable generated in the initialization process by continuous uniform distributions.

Considering the maximum possible demand at each bus during the planning horizon to provide the demands and charge the ESSs. The binary control variables representing the unit commitment status of the DG units 
and those that refer to the time periods with financial incentives for the demand reduction are also randomly generated during the initialization process. Figure 3 shows the flowchart of the proposed approach for the multi-objective optimization problem of REPs in the short-term markets.

\section{Simulation Results}

The IEEE 24 bus reliability test system (Fig. 4) is modified in this section to include the retailers as participants of the electricity market. It is assumed that each retailer is serving loads at several buses and their assets are located in the distribution networks that are connected to that bus. In Fig. 4, the buses that each retailer is serving loads in them are connected to the retailers with dashed red lines. The retailers participate in the transmission-level wholesale electricity market and purchase the demand of the customers that they serve in the distribution network. Retailers set up their optimal plans based on the probabilistic LMPs and the uncertainty in load profile of the customers. Based on main structure materials and the storage mechanism, the rechargeable batteries are categorized in several types. Each type of batteries has individual planning features. The characteristics of the ESSs that the retailers own in distribution networks are shown in Table 2. Each retailer may have one or more ESSs at each of the buses that they serve loads. In Table 3, the characteristics of the DG units that each retailer owns in the distribution network are presented. Four price taker retailers out of many retailers that are serving loads in this system are selected in this section to analyze their optimal scheduling. These retailers serve 30 customer groups at the buses shown in test system. The demand for each customer group without uncertainty is shown in Fig. 5. These customers have signed contracts with the electricity retailers and the retail rates are specified in advance. In Fig. 6, the electricity retail rates of the customers with the retailers are shown. In this section, the day-ahead the probabilistic LMP and load demand are used for the scheduling horizon of $24 \mathrm{~h}$.

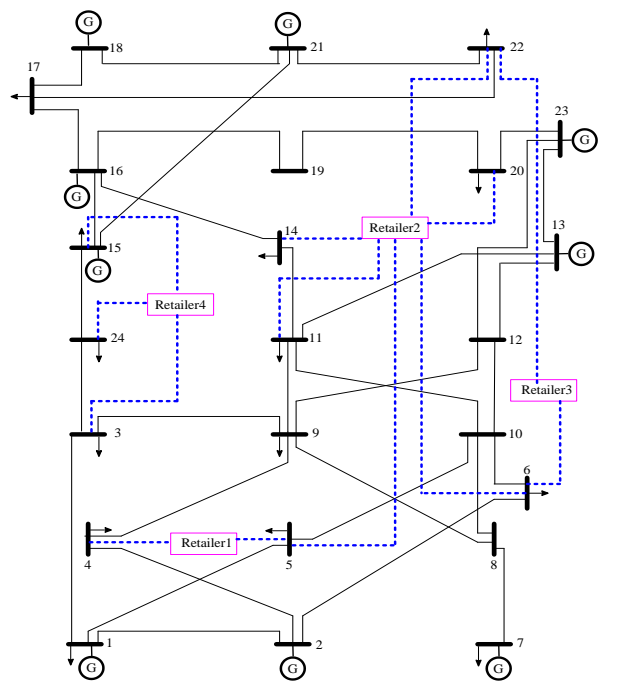

Fig. 4. Modified IEEE 24 bus reliability case study.
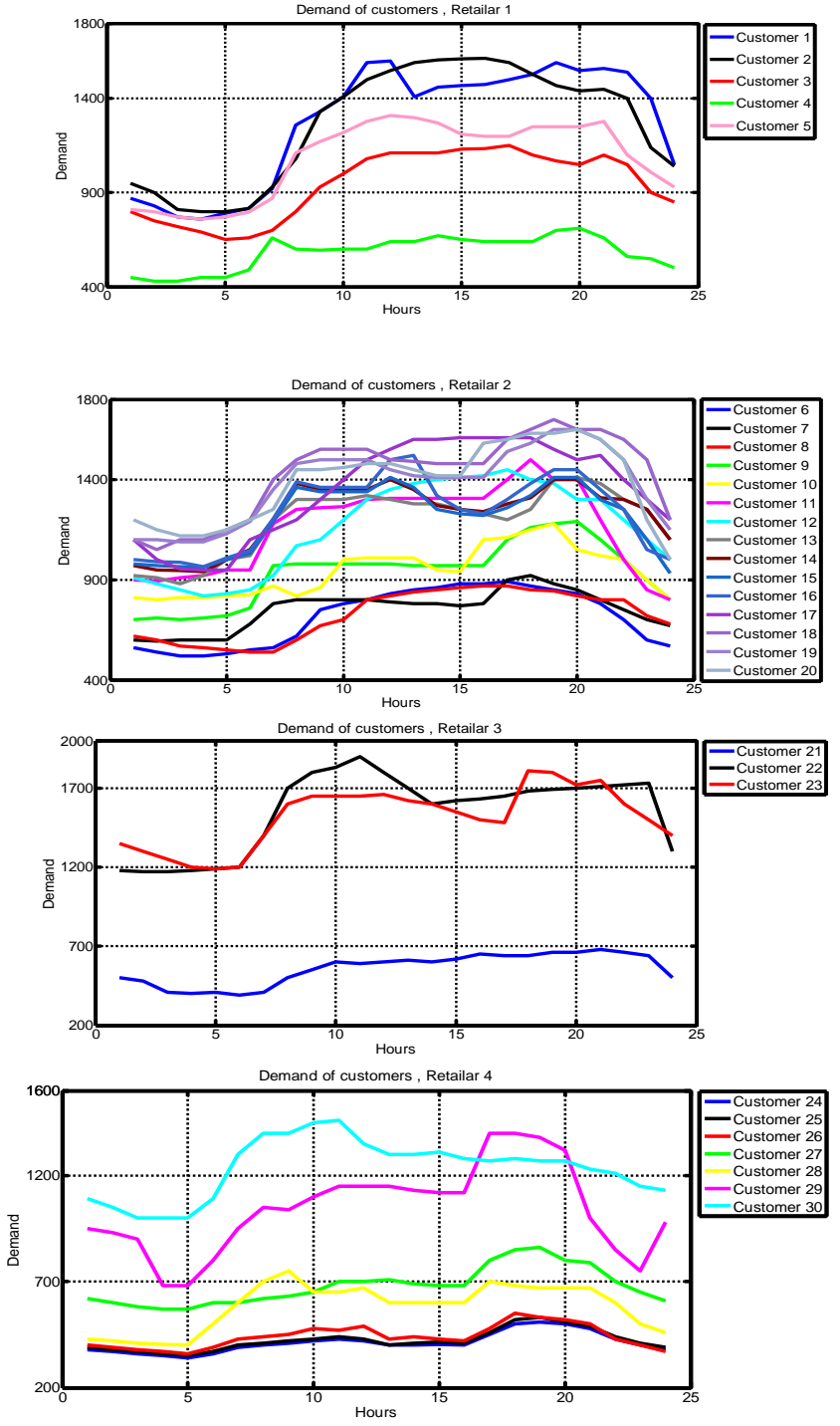

Fig. 5. Demand for each customer group without uncertainty

Table. 2. Mean value of parameters of battery technologies [34].

\begin{tabular}{|c|c|c|c|c|c|c|c|}
\hline Retailers & ESSs & $\begin{array}{c}\text { Maximum } \\
\text { energy } \\
\text { level } \\
(\mathrm{kWh})\end{array}$ & $\begin{array}{c}\text { Minimum } \\
\text { energy } \\
\text { level } \\
(\mathrm{kWh})\end{array}$ & $\begin{array}{c}\text { Charging } \\
\text { rate } \\
(\mathrm{kW} / \mathrm{h})\end{array}$ & $\begin{array}{l}\text { Discharging } \\
\text { rate }(\mathrm{kW} / \mathrm{h})\end{array}$ & $\begin{array}{l}\text { Initial } \\
\text { energy } \\
(\mathrm{kW} / \mathrm{h})\end{array}$ & Buses \\
\hline \multirow[b]{2}{*}{1} & 1 & 1245 & 316 & 254 & 186 & 426 & 4 \\
\hline & 2 & 808 & 101 & 98 & 103 & 203 & 5 \\
\hline \multirow{9}{*}{2} & 3 & 1942 & 544 & 355 & 405 & 710 & 14 \\
\hline & 4 & 1613 & 298 & 475 & 454 & 356 & 14 \\
\hline & 5 & 2803 & 396 & 522 & 616 & 2436 & 20 \\
\hline & 6 & 1894 & 305 & 468 & 402 & 354 & 22 \\
\hline & 7 & 2303 & 535 & 487 & 609 & 693 & 6 \\
\hline & 8 & 1619 & 278 & 324 & 347 & 292 & 6 \\
\hline & 9 & 2441 & 485 & 392 & 637 & 536 & 5 \\
\hline & 10 & 1803 & 496 & 423 & 508 & 628 & 11 \\
\hline & 11 & 2539 & 510 & 378 & 585 & 598 & 11 \\
\hline \multirow{5}{*}{3} & 12 & 1533 & 432 & 277 & 310 & 555 & 22 \\
\hline & 13 & 996 & 210 & 241 & 234 & 377 & 22 \\
\hline & 14 & 1397 & 412 & 177 & 171 & 523 & 22 \\
\hline & 15 & 1006 & 310 & 286 & 316 & 476 & 6 \\
\hline & 16 & 1562 & 415 & 229 & 199 & 491 & 6 \\
\hline \multirow{4}{*}{4} & 17 & 1440 & 230 & 311 & 434 & 263 & 15 \\
\hline & 18 & 910 & 190 & 205 & 270 & 571 & 24 \\
\hline & 19 & 1790 & 521 & 388 & 320 & 619 & 3 \\
\hline & 20 & 1706 & 386 & 249 & 334 & 435 & 3 \\
\hline
\end{tabular}


Table. 3. Technical and cost characteristics of DG units.

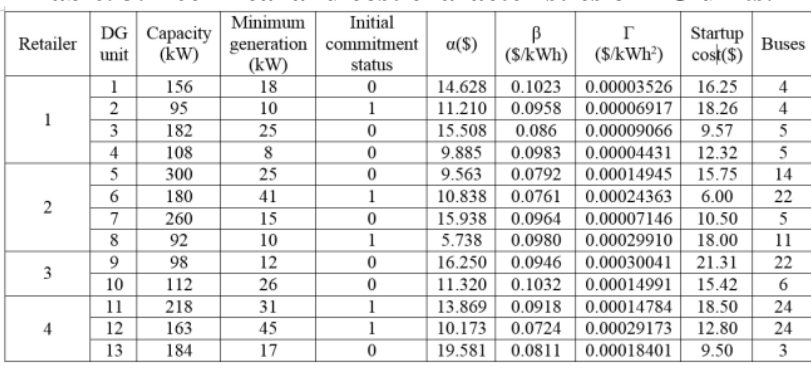

In Table 4, the data that the retailer needs to calculate the optimal DR schedules is presented. It is assumed that the retailers can achieve a good fit of this function with a polynomial regression model. The coefficients of the quadratic functions that have been used to model the elasticity of end-users toward financial incentives for the demand reduction are shown in this table. The retailers obtain this information by repeatedly interacting with the electricity end-users. The bus that each customer is located is also given in this Table. In order to find the optimal type of batteries, two case studies are considered in this study. In case 1 , the main purpose is to show the effectiveness of the proposed model and the NSGA-II algorithm in solving the short-term problems of electricity retailers with $\mathrm{Na}-\mathrm{S}$ battery technology and in case 2 the electricity retailers equipped with $\mathrm{Zn}-\mathrm{Br}$ battery technology.

In order to verify the simulation method, at first the model has been developed based on the reference paper [17] and comparative study has been implemented and then the improved model has been extended.

\section{Case 1:}

The multi-objective optimization problem is solved in this section with the NSGA-II. The battery technology for retailers is Na-S. Fig. 7 illustrates the Pareto front of the optimization problem solved by the NSGA-II. The suitable values for the parameters of the algorithm are determined empirically by running some trial simulations. The best algorithm parameters that regulate the crossover and mutation operators are given for this case study in Table 5. The financial incentives that the retailers offer to the end-users for retailer 1 in this case are shown in Table 6.

\section{Case 2:}

In Fig. 8, the Pareto fronts obtained by the NSGA-II for the all retailers that used from $\mathrm{Zn}-\mathrm{Br}$ battery technology are presented. As shown in this Figure, two of the retailers ( 3 and 4 ) are expecting negative payoffs (i.e., financial losses) in the day-ahead market. Employing the strategies can only reduce the financial losses and does not make any profit for them. The optimal points are shown in Fig. 8 by the pointers.
Table. 4. DR characteristics of end-users.

\begin{tabular}{|c|c|c|c|c|c|c|c|}
\hline \multirow{2}{*}{ Customers } & \multirow{2}{*}{$\begin{array}{c}\text { Baseline } \\
\text { load }\end{array}$} & \multicolumn{3}{|c|}{$\Delta I=\alpha_{2} \cdot F I^{2}+\alpha_{1} \cdot F I+\alpha_{0}$} & \multirow{2}{*}{$\begin{array}{l}\text { Minimum } \\
\text { incentive }\end{array}$} & \multirow{2}{*}{$\begin{array}{l}\text { Maximum } \\
\text { incentive }\end{array}$} & \multirow{2}{*}{ Buses } \\
\hline & & $\alpha_{2}$ & $\alpha_{1}$ & $a_{0}$ & & & \\
\hline 1 & 1250.0 & 659051.76 & -38968 & 511.24 & 0.0186 & 0.0514 & 4 \\
\hline 2 & 1300 & -173868.8 & 23179.4 & -433.3 & 0.0242 & 0.0526 & 4 \\
\hline 3 & 950 & 144351.38 & -7783.9 & 105.7 & 0.0195 & 0.0632 & 5 \\
\hline 4 & 550 & 34860.79 & 1292.0 & -41.04 & 0.0268 & 0.0578 & 5 \\
\hline 5 & 1000 & 507587.06 & -38942 & 620.2 & 0.0209 & 0.0676 & 5 \\
\hline 6 & 780 & 259722.48 & -15808 & 268.0 & 0.0273 & 0.0493 & 14 \\
\hline 7 & 1000 & 17087.38 & 2198.7 & -12.81 & 0.0364 & 0.0580 & 14 \\
\hline 8 & 1450 & -323228.5 & 36284.9 & -795.4 & 0.0362 & 0.0578 & 14 \\
\hline 9 & 1350 & -60611.03 & 9572.42 & -165.8 & 0.0419 & 0.0632 & 20 \\
\hline 10 & 1500 & -323835.0 & 37347.0 & -860.4 & 0.0372 & 0.0587 & 22 \\
\hline 11 & 1250 & -418218.2 & 47406.3 & -1173 & 0.0404 & 0.0617 & 22 \\
\hline 12 & 650 & 424638.1 & -30095 & 572.8 & 0.0282 & 0.0501 & 22 \\
\hline 13 & 1350 & -156061.7 & 16426 & -176.7 & 0.0289 & 0.0508 & 6 \\
\hline 14 & 1500 & -687791.4 & 68344 & -1453 & 0.0370 & 0.0585 & 6 \\
\hline 15 & 1200 & -955117.6 & 92717 & -1944 & 0.0357 & 0.0573 & 5 \\
\hline 16 & 1250 & -338477.5 & 32567.7 & -521 & 0.0265 & 0.0485 & 11 \\
\hline 17 & 1200 & 2157991.5 & -201295 & 4646 & 0.0378 & 0.0593 & 11 \\
\hline 18 & 950 & -55310.98 & 9798.6 & -168.9 & 0.0304 & 0.0522 & 11 \\
\hline 19 & 1250 & -40451.16 & 6994.44 & -116.4 & 0.0388 & 0.0602 & 11 \\
\hline 20 & 800 & 37968.77 & -294.41 & 34.51 & 0.0290 & 0.0509 & 11 \\
\hline 21 & 1550 & -996162.4 & 84506.6 & -1533 & 0.0267 & 0.0454 & 22 \\
\hline 22 & 575 & -89542.85 & 11355.2 & -247.4 & 0.0310 & 0.0659 & 6 \\
\hline 23 & 1550 & -15900.84 & 8655.4 & -211.8 & 0.0293 & 0.0547 & 6 \\
\hline 24 & 1100 & 207895.0 & -11170 & 180.3 & 0.0297 & 0.0640 & 15 \\
\hline 25 & 605 & 187256.7 & -10889 & 164.9 & 0.0220 & 0.0528 & 15 \\
\hline 26 & 1250 & -271774.8 & 28120.3 & -502.2 & 0.0248 & 0.0466 & 24 \\
\hline 27 & 412.5 & $\begin{array}{l}-199752.3 \\
\end{array}$ & 19079 & -334.9 & 0.0255 & 0.0536 & 24 \\
\hline 28 & 698 & -154248.6 & 17154.3 & -306.5 & 0.0246 & 0.0572 & 24 \\
\hline 29 & 450.5 & -10023.81 & 3219.4 & -85.65 & 0.0367 & 0.0717 & 3 \\
\hline 30 & 495.5 & 212974.62 & -16100 & 343.5 & 0.0359 & 0.0563 & 3 \\
\hline
\end{tabular}

Table. 5. Best parameters for $24 \mathrm{~h}$ scheduling

\begin{tabular}{|c|c|}
\hline Parameters & Values \\
\hline Population size & 1500 \\
\hline Number of iterations & 1250 \\
\hline Crossover probability & 0.80 \\
\hline Mutation Probability & 0.30 \\
\hline Mutation rate & 0.03 \\
\hline \multirow{2}{*}{ Mutation strength } & $\begin{array}{c}10 \% \text { of the variable range (max- } \\
\text { min) }\end{array}$ \\
\hline$\sigma$ (range of arithmetic crossover) & 0.03 \\
\hline
\end{tabular}

Table. 6. Financial incentives for the customers of retailer 1 (\$) in case 1.

\begin{tabular}{|l|l|l|l|l|}
\hline bus & Customer 1 & Customer 2 & Customer 3 & Customer 4 \\
\hline 8 & - & - & - & 0.0634 \\
\hline 9 & - & 0.0549 & - & 0.0612 \\
\hline 10 & - & 0.0551 & - & 0.0629 \\
\hline 11 & 0.0520 & 0.0563 & - & 0.0641 \\
\hline 12 & 0.0514 & 0.0539 & - & 0.0610 \\
\hline 13 & 0.0503 & 0.0530 & - & 0.0596 \\
\hline 14 & 0.0510 & 0.0572 & - & 0.0610 \\
\hline 15 & 0.0547 & 0.0589 & - & 0.0539 \\
\hline 16 & 0.0512 & 0.0551 & - & 0.0608 \\
\hline 17 & 0.0513 & 0.0564 & - & 0.0642 \\
\hline 18 & - & - & - & 0.0626 \\
\hline 19 & 0.0543 & 0.0570 & - & 0.0614 \\
\hline 20 & - & 0.0593 & - & 0.0653 \\
\hline 21 & 0.0505 & 0.0585 & 0.592 & 0.0684 \\
\hline 22 & 0.0544 & - & - & 0.0669 \\
\hline 23 & 0.0536 & - & - & 0.0639 \\
\hline
\end{tabular}

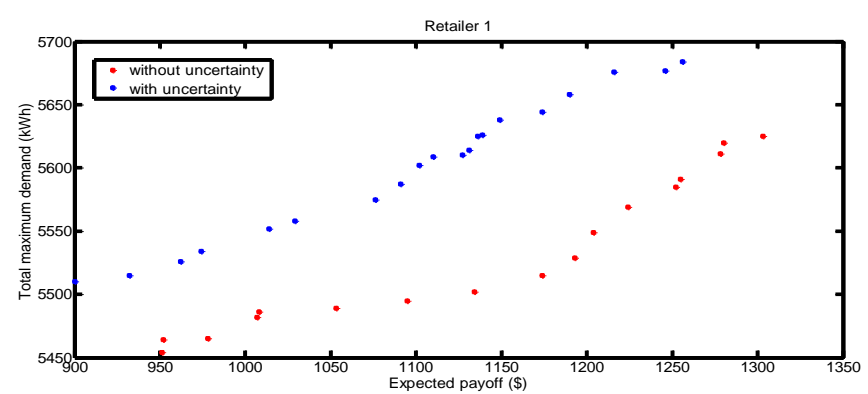



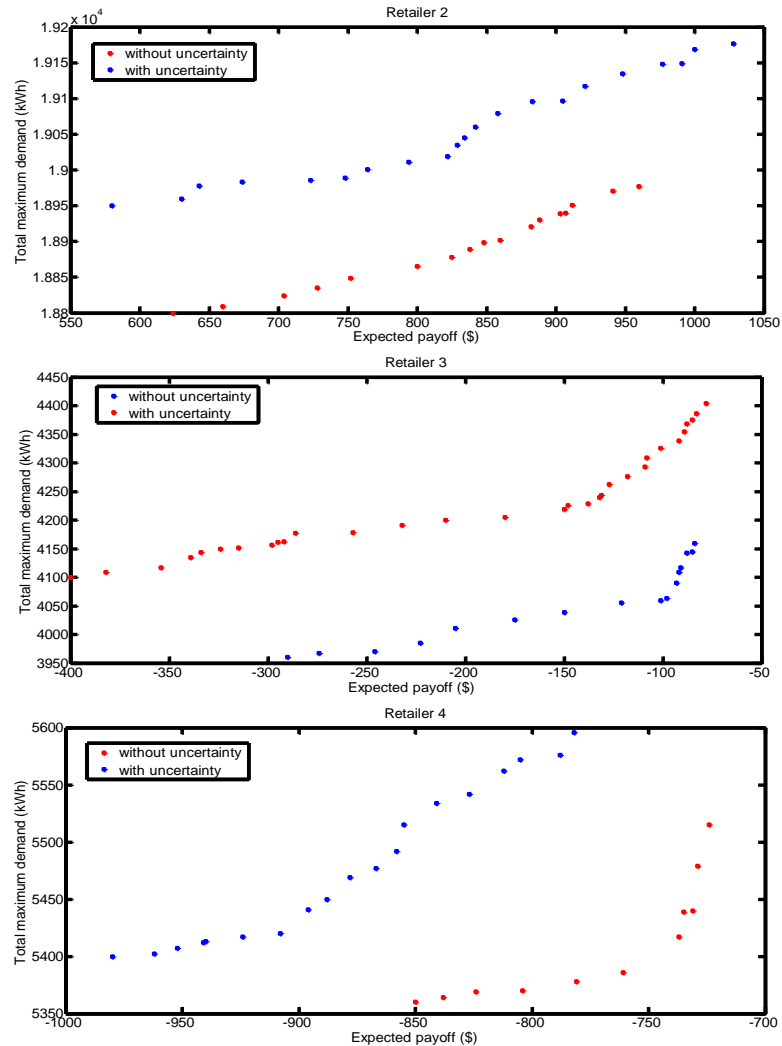

Fig. 7. Pareto front for retailers at case 1.

The results are compared with the case that the retailer implements all their physical assets and the DR programs. The optimal points in the Pareto front change in a relatively small range when the ESSs or DR programs are considered solely. It is due to the charging and discharging limits of the ESSs, the ESSs' capacity for storage and the limitations of customers in reducing their consumption. These assets and strategies can provide a wide range of options for the decision maker, when they are considered with the DG units located in the distribution network. It is obvious that the $\mathrm{Zn}-\mathrm{Br}$ battery technology is suitable than $\mathrm{Na}-\mathrm{S}$ battery in uncertain conditions.

\section{Conclusions}

In this paper, a multi-objective decision-making framework was developed for retail electricity providers with light physical assets to schedule their resources to optimize the financial losses. The selected optimal points are expected payoff 1220 (\$) in maximum demand $5580(\mathrm{kWh})$ for retailer $(1)$, expected payoff $1050(\$)$ in maximum demand $19400(\mathrm{kWh})$ for retailer (2), expected payoff $-60(\$)$ in maximum demand $4360(\mathrm{kWh})$ for retailer (3), expected payoff -725 (\$) in maximum demand $5650(\mathrm{kWh})$ for retailer (4). By using the proposed framework, the REPs are able to make trade-off decisions considering the conflicting targets of minimizing the peak demand and maximizing the profit in order to incentive-based DRP in retail markets. Fuzzy logic modeling is employed for simulating load uncertainty on the locational marginal prices. Considering the complexity and non-linearity of the proposed model, NSGA-II is used. The Modified IEEE 24 bus reliability case study findings show that the designed DRPs can provide and guarantee the short-term benefits of REPs in electricity markets.
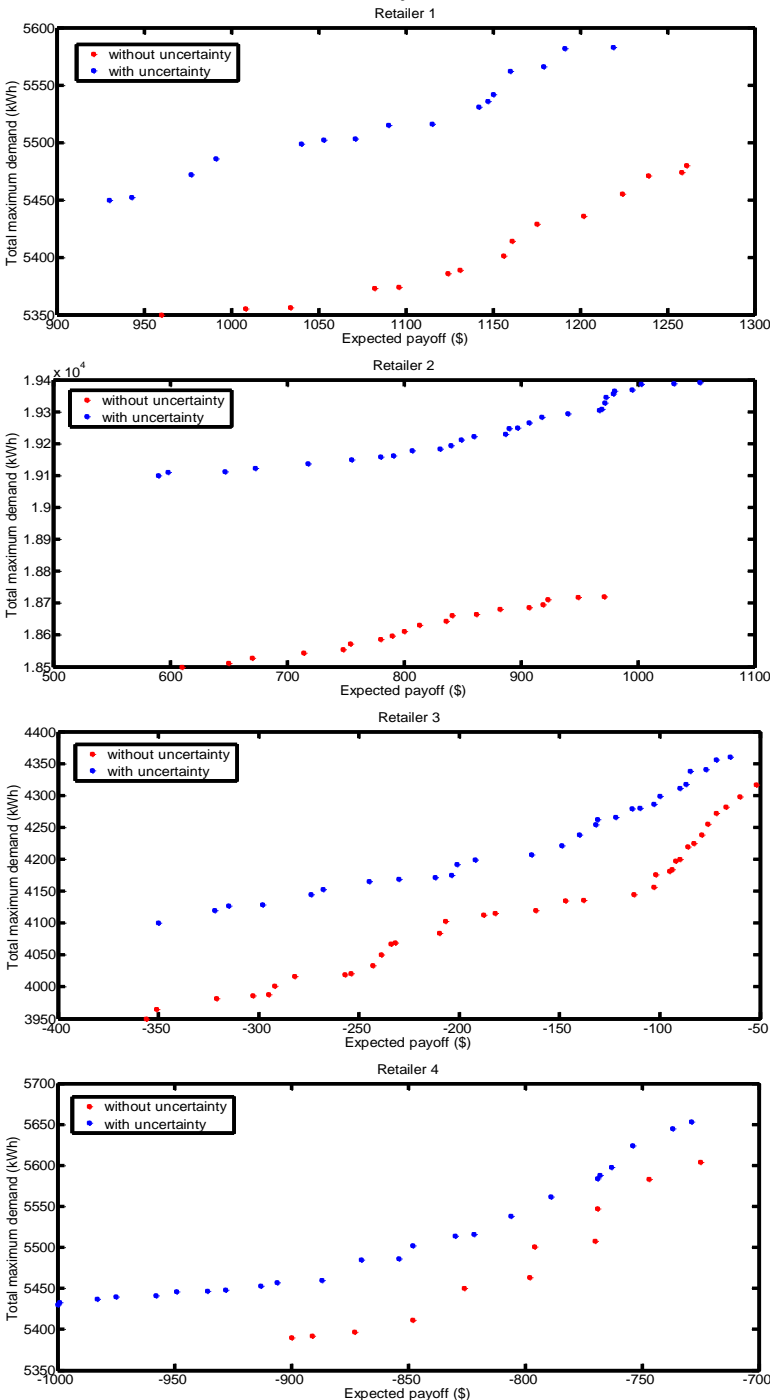

Fig. 8. Pareto front for retailers at case 2 .

\section{References}

[1] M. Carrión, A.J.Conejo, and J.M.Arroyo, "Forward contracting and selling price determination for a retailer," IEEE. Trans. Power Syst, pp.2105-2114, 2007.

[2] S. Nojavan, K. Zare, B. Mohammadi-ivatloo, "Optimal stochastic energy management of retailer based on selling price determination under smart grid environment in the presence of demand response program," Appl. Energy, pp.449-464, 2017.

[3] J. Torriti, M.G. Hassan, M. Leach, "Demand response experience in Europe policies, programmers and implementation," Energy, pp.1575-1583, 2010.

[4] R. Sharifi, S.H. Fathi, V. Vahidinasab, "A review on Demand-side tools in electricity market," Renewable and Sustainable Energy Reviews, Vol. 72, pp. 565-572, 2017.

[5] O. Erdinc, "Economic impacts of small-scale own generating and storage units, and electric vehicles under different demand response strategies for smart households,"Appl.Energy, pp.142, 2014

[6] P. T. Baboli, "Designing Incentive-based Demand Response Program for Minimizing Financial Risk of Retailer during Peak Period", Journal of Iranian 
Association of Electrical and Electronics Engineers, Vol. 15,No. 14, pp. 93-102, 2019.

[7] W. Lee, B. O Kang, J. Jung, "Development of energy storage system scheduling algorithm for simultaneous self-consumption and demand response program participation in South Korea," Energy. pp. 963-973, 2018.

[8] T. Khalili, A. Jafari, M. Abapour, B. MohammadiIvatloo, "Optimal battery technology selection and incentive-based demand response program utilization for reliability improvement of an insular microgrid ," Energy. pp. 92-104, 2019.

[9] J. Xie, T. Hong, J. Stroud, "Long-term retail energy forecasting with consideration of residential customer attrition," IEEE. Trans. Smart Grid, pp.2245, 2015.

[10] S. Gabriel, MF. Genc, S. Balakrishnan, "A simulation approach to balancing annual risk and reward in retail electrical power markets," IEEE. Trans. Power Syst pp.1050, 2002

[11] S. Nojavan, M. Mehdinejad, K. Zare, B. MohammadiIvatloo, "Energy procurement management for electricity retailer using new hybrid approach based on combined BICA-BPSO," Int. J. Electr. Power. Energy Syst, 2015.

[12] S. Feuerriegel, D. Neumann, "Measuring the financial impact of demand response for electricity retailers," Energy. Pol, 2014

[13] M. Charwand, A. Ahmadi, P. Siano, V. Dargah, D. Sarno, "Exploring the trade-off between competing objectives for electricity energy retailers through a novel multi-objective framework," Energy. Convers. Manage, 2015.

[14] M. Charwand, A. Ahmadi, AR. Heidari, A. Esmaeel Nezhad, "Benders decomposition and normal boundary intersection method for multiobjective decision making framework for an electricity retailer in energy markets," IEEE. Syst.J, 2015.

[15] AR. Hatami, H. Seifi, MK. Sheikh-El-Eslami, "Optimal selling price and energy procurement strategies for a retailer in an electricity market, " Electr Power Syst Res, 2009.

[16] A. Ahmadi, M. Charwand, J. Aghaei, "Risk-constrained optimal strategy for retailer forward contract portfolio," Int J Electr Power Energy Syst, 2013.

[17] MA. Ghazvini, J. Soares, N. Horta, R. Neves, R. Castro, Z. Vale, "A multi-objective model for scheduling of short-term incentive-based demand response programs offered by electricity retailers, " Appl Energy, 2015.

[18] M. Zugno, JM. Morales, P. Pinson, H. Madsen, "A bilevel model for electricity retailers' participation in a demand response market environment," Energy Econ, 2013.

[19] W. Wei, F. Liu, S. Mei, "Offering non-dominated strategies under uncertain market prices," IEEE Trans Power Syst, 2015.

[20] M. Khojasteh, S. Jadid, "Decision-making framework for supplying electricity from distributed generation-owning retailers to price-sensitive customers," Utilities Policy, 2015.

[21] J. C, Prado, W. Qiao, " A Stochastic Decision-Making Model for an Electricity Retailer With Intermittent Renewable Energy and Short-Term Demand Response," IEEE. Trans. Smart Grid, pp.2581-2592, May 2019.

[22] W. Wei, F. Liu, S. Mei, "Energy pricing and dispatch for smart grid retailers under demand response and market price uncertainty," IEEE Trans Smart Grid, 2015.
[23] R. Herranz, A. Munoz San Roque, J. Villar J, FA. Campos, "Optimal demand-side bidding strategies in electricity spot markets," IEEE Trans Power Syst, 2012.

[24] H.R. Arasteh, M. Parsa Moghaddam, M.K. Sheikh-El Eslami, M. Shafie-Khah, "Bidding Strategy in demand response Exchange Market," Journal of Iranian Association of Electrical and Electronics Engineers, Vol.10, Issue 2, pp. 1-10, 2013

[25] S. Nojavan, K. Zare, " Optimal energy pricing for consumers by electricity retailer," Int J Electr Power Energy Syst, pp. 401-412, 2018.

[26] A. Gomes, Antunes Carlos Henggeler, E. Oliveira, "Direct load control in the perspective of an electricity retailer - a multi-objective evolutionary approach," Soft Comput Ind Appl, 2011.

[27] K. Deb, A. Pratap, S. Agarwal and T. Meyarivan, "A Fast and Elitist Multiobjective Genetic Algorithm: NSGA-II," IEEE Transactions on Evolutionary Computation, 2002.

[28] JS. Vardakas, N. Zorba, CV. Verikoukis, "A survey on demand response programs in smart grids: pricing methods and optimization algorithms," IEEE Commun Surv Tut, 2015.

[29] M. Daghi, M. Sedghi, A. Ahmadian, M. Aliakbar-Golkar, "Factor analysis based optimal storage planning in active distribution network considering different battery technologies," Applied energy, 2016.

[30] C. Kahraman, S. Cevik Onar, "Intelligent techniques in engineering management: theory and applications," Switzerland: Springer, 2015.

[31] AT. Saric, RM. Ciric, "Integrated fuzzy state estimation and load flow analysis in distribution networks," IEEE Trans Power Delivery, 2003.

[32] MR. Haghifam, OP. Malik, "Genetic algorithm-based approach for fixed andswitchable capacitors placement in distribution systems with uncertainty andtime varying loads," IET Gener Transm Distrib, 2007.

[33] S. Ganguly, NC. Sahoo, D. Das, "Multi-objective particle swarm optimization based on fuzzy-Pareto-dominance for possibilistic planning of electrical distribution systems incorporating distributed generation," Fuzzy SetsSyst, 2013. http://dx.doi.org/10.1016/j.fss.2012.07.005

[34] B. Zakeri, S. Sanna, "Electrical energy storage systems: a comparative life cycle cost analysis," Renew Sustain Energy Rev, 2015.

[35] VSKM. Balijepalli, V. Pradhan, SA. Khaparde, "Chapter 3: demand response under smart grid paradigm. Smart microgrids new Adv,"Challenges Oppor. Actual Power Syst. Nova Science Publishers; pp.53-118, 2013.

[36] W. Yu, D. Liu, Y. Huang, "Operation optimization based on the power supply and storage capacity of an active distribution network," Energies, 2013.

[37] E. Litvinov "Design and operation of the locational marginal prices-based electricity markets," Gener. Transm. Distrib. IET 4, 2010.

[38] Y. Fu, Z. Li, "Different models and properties on LMP calculations," Power Engineering Society General Meeting, IEEE, 2006.

[39] Ghasem Derakhshan, Heidar Ali Shayanfar, Ahad Kazemi, "Optimal design of solar PV-WT-SB based smart microgrid using NSHCSO," International. Journal of Hydrogen Energy, Volume 41, Issue 44, 26, pp.1994719956, November 2016

[40] K. Deb, R. Steuer, R.Tewari, "Bi-objective portfolio optimization using a customized hybrid NSGA-II procedure," Evol Multi-Criterion Optim 2011. 